\title{
Severe community-acquired pneumonia in general medical wards: outcomes and impact of initial antibiotic selection
}

\author{
Phunsup Wongsurakiat ${ }^{1 *}$ (D) and Napat Chitwarakorn ${ }^{2}$
}

\begin{abstract}
Background: Most international guidelines recommend empirical therapy for community-acquired pneumonia (CAP) to be based on site of care. Some patients with severe CAP are managed in general wards because of limited intensive care unit (ICU) bed or because of unrecognition of the pneumonia severity. Appropriate initial antibiotic treatment for severe CAP outside ICU has not yet been established. This study aimed to determine the prevalence and the impact of initial antibiotic selection on the outcomes of patients with severe CAP who were admitted and managing in general wards.

Methods: This prospective observational study included consecutive patients hospitalized for presumed CAP in general wards over a 1-year period. Severe CAP was identified using the 2007 Infectious Diseases Society of America (IDSA)/ American Thoracic Society (ATS) criteria. Initial antibiotic treatment in the first $24 \mathrm{~h}$ were collected. The primary outcome was the rate of unfavorable outcome (composite outcome of treatment failure and in-hospital death). The secondary outcome was the number of hospital-free days assessed 30 days after enrollment into the study.

Results: There were 94 patients hospitalized with CAP of which 50 (53.2\%) patients were compatible with severe CAP. An etiologic diagnosis was found in 43 (45.8\%) patients. The most common pathogens identified in patients with severe CAP were Staphylococcus aureus (28.6\%) and Klebsiella pneumoniae (28.6\%), followed by Pseudomonas aeruginosa (17.9\%). Patients with severe CAP had significantly more positive blood culture than patients with non-severe CAP (24\% VS 4.5\%; $p=.008)$. Initial antibiotic treatment were discordant with the IDSA ATS guidelines in $42 \%$ of all patients hospitalized with CAP, and 52\% of patients with severe CAP. Multivariate analysis revealed that age (OR 1.1,95\% Cl 1.01-1.1) and initial antibiotic treatment discordant to guidelines for severe CAP in ICU (OR 4.6, 95\% Cl 1.3-17.1) were independent risk factors of the unfavorable outcome of patients with severe CAP. Patients with unfavorable outcome had lower number of hospital-free days than patients with favorable outcome ( $5.2 \pm 8$ days VS $18 \pm 7.1$ days; $p<.001)$.
\end{abstract}

Conclusions: Patients with severe CAP outside ICU should be recognized for appropriate initial antibiotic selection to improve outcomes.

Keywords: Antibiotic, Hospital-free days, Intensive care unit, Mortality, Outcome, Treatment failure

\footnotetext{
* Correspondence: phunsup.won@mahidol.ac.th

${ }^{1}$ Division of Respiratory Disease, Department of Medicine, Siriraj Hospital,

Mahidol University, Bangkoknoi, Bangkok 10700, Thailand

Full list of author information is available at the end of the article
}

(c) The Author(s). 2019 Open Access This article is distributed under the terms of the Creative Commons Attribution 4.0 International License (http://creativecommons.org/licenses/by/4.0/), which permits unrestricted use, distribution, and reproduction in any medium, provided you give appropriate credit to the original author(s) and the source, provide a link to the Creative Commons license, and indicate if changes were made. The Creative Commons Public Domain Dedication waiver (http://creativecommons.org/publicdomain/zero/1.0/) applies to the data made available in this article, unless otherwise stated. 


\section{Background}

Community-acquired pneumonia (CAP) is a leading cause of hospitalization and death worldwide [1-5]. Severe CAP is a group of patients who have severe disease with poor outcomes and requiring a higher level of care [6, 7]. Several criteria have been proposed to define severe CAP. Most reports have defined it simply as CAP that necessitates intensive care unit (ICU) admission.

Initial treatment of CAP is usually empirical, because the microbial etiology cannot be predicted on the basis of clinical presentation. Most international guidelines recommend empirical therapy that is based on the location of care, with specific recommendations for those managed as outpatients, as inpatients, and in ICUs [7-10]. Adherence to initial antibiotic selection guidelines was reported to be associated with improved survival and reduced duration of mechanical ventilation of patients with severe CAP in ICU [11-14].

ICU admission policies and the availability of ICU beds varies widely across the world. The shortage of ICU beds is a daily problem in many hospitals, especially in underresourced countries [15-18]. Moreover, there is a category of severe CAP classified by the 2007 Infectious Diseases Society of America (IDSA)/American Thoracic Society (ATS) minor criteria [7] that may be under-recognized because patients may initially present with subtle findings [7, 19]. As many as $45 \%$ of patients with CAP who ultimately required ICU admission were initially admitted to a non-ICU setting [20]. As a result, in many hospitals, a substantial number of patients with severe CAP might be managed mainly in general wards due to either limited number of ICU beds or under-recognition of pneumonia severity.

To the best of our knowledge, no study has yet specifically focused on the outcomes and impact of initial antibiotic treatment in patients with severe CAP that are admitted to general wards. One previous study reported that using IDSA/ATS minor criteria to early identify patients at risk for severe CAP combined with an aggressive emergency department resuscitation bundle, including initial antibiotic treatment protocol, may reduce mortality in this group of patients [21]. Accordingly, we set forth to study the prevalence and outcomes of patients with severe CAP who were admitted to and managed mainly in general wards, and to evaluate the impact of initial antibiotic selection on outcomes. Our working hypothesis was that the discordant site of care (i.e., general medical wards) would influence initial antibiotic selections that are discordant with IDSA/ATS initial antibiotic selection guidelines for patients with severe CAP in ICU, and that this might contribute to poorer outcomes.

\section{Methods}

\section{Study population}

This study is a secondary analysis of the data collected from a prospective observational study conducted from
November 2012 to November 2013 at a 2500-bed university-based hospital in Thailand. The study aimed to determine the prevalence and outcomes of healthcareassociated pneumonia in the authors' hospital. Our hospital has two sections: a private section and a general section. In the general section, we have around 2200 inpatient beds. The Department of Medicine has 462 inpatient beds comprise 160 general medical ward beds, 186 private beds, 76 special disease beds (such as stroke unit, bone marrow transplant unit) and 40 critical care beds (15 general ICU beds, 10 critical respiratory care beds and 15 cardiac care beds). This study was performed in 8 general medical wards affiliated with the Department of Medicine (160 beds).

Each general medical ward had a 20-patient capacity. Patients were managed by a medical team consisted of an attending physician, 1 third year resident in general internal medicine, 2 first year residents in general internal medicine and 3 to 4 interns rotated to work in the Department of Medicine. Attending physicians were board certified in internal medicine, with minimal critical care training. The medical team were rotated monthly. There were approximately 4 nurses and 4 nurse assistants doing nursing care for the patients.

Due to a shortage of ICU bed, patients who required mechanical ventilation were often admitted directly to a general medical ward. Patients mechanically ventilated on the wards were managed by the same attending physicians that treated non-ventilated patients on the wards. Upon request, some patients were continuous monitoring with electrocardiography, noninvasive blood pressure monitoring and oxygen saturation by pulse oximetry.

Consecutive patients admitted to 1 of 8 general medical wards affiliated with the Department of Medicine, were potentially eligible for this study. Patients that met all of the following criteria were included: age $>18$ years, admitted from outside the hospital for presumed pneumonia with symptoms of acute respiratory infection (fever, cough, pleuritic chest pain, or dyspnea), and presence of new infiltrate on chest radiograph. Patients that were pregnant, that were enrolled in another trial, that had received immunosuppressants or long-term corticosteroid therapy, that had concomitant acquired immunodeficiency syndrome, that had undergone tracheotomy, or that had a preexisting medical condition with a life expectancy of less than 3 months were excluded. Enrolled patients were excluded during the follow-up period if patients were subsequently transferred to the ICU within 5 days after admission or the etiology of pneumonia was found to be mycobacteria or fungi.

\section{Study design and data collection}

A protocol for data collection in the first $24 \mathrm{~h}$ was applied in all cases. Information that was collected included age, gender, smoking status, residence, comorbidities (pulmonary, heart, liver, neurologic, renal, neoplasms, and diabetes 
mellitus), enteral tube feeding, receiving chronic hemodialysis or wound care, hospitalization within the last 90 days, and broad-spectrum antibiotic therapy within the previous 90 days. Functional status was assessed using Eastern Cooperative Oncology Group (ECOG) scale of performance status [22].

The following clinical data were recorded: mental alterations, temperature, heart rate, respiratory rate, and blood pressure. For severity of illness, we assessed the need for mechanical ventilation and/or vasopressors within $24 \mathrm{~h}$ of admission. Chest radiographic findings were also documented (number of affected lung lobes, presence of pleural effusion). Recorded laboratory data were complete blood count, chemical parameters, and arterial blood gas analysis.

Microbiological studies included blood cultures, and collection of a sputum sample, pleural fluid, or bronchoalveolar lavage for Gram stain and culture, when possible. Only specimens obtained within $72 \mathrm{~h}$ before or after admission were included. Etiologic diagnosis was considered definitive in the following situations: isolation of a respiratory pathogen in a usually sterile specimen (blood, pleural fluid) or bacterial growth in bronchoalveolar lavage fluid $\left(\geq 10^{4} \mathrm{cfu} / \mathrm{ml}\right)$. Etiologic diagnosis was considered presumptive when a predominant microorganism was isolated from a sputum sample $(>25$ polymorphonuclear leukocytes and $<10$ squamous cells per low-power field).

Initial antibiotic treatment prescribed within the first $24 \mathrm{~h}$, and whether the clinician later had to modify the initial antibiotic regimen was recorded. Antibiotic prescriptions were left to the discretion of the attending physician and were not protocolized. No interventions relative to the prescribing physicians were effectuated prior to or during the study.

The study protocol was approved by the Siriraj Hospital Ethics Committee on Human Research (No. SIRB 391/2555-EC1). Written informed consent for inclusion in the study was obtained from each patient or the patient's next of kin.

\section{Definitions}

Severe CAP was defined according to IDSA/ATS criteria [7] as follows: (1) having 1 or more of the major criteria (invasive mechanical ventilation or septic shock with a need for vasopressors); (2) having 3 or more of the minor criteria (respiratory rate $\geq 30$ breaths $/ \mathrm{min}$, $\mathrm{PaO}_{2} / \mathrm{FiO}_{2} \leq 250 \mathrm{mmHg}$, multilobar infiltrates, confusion/disorientation, blood urea nitrogen (BUN) $\geq 20 \mathrm{mg} /$ $\mathrm{dL}, \mathrm{WBC}$ count $<4000$ cells $/ \mathrm{mm}^{3}$, platelet count $<100$, 000 cells $/ \mathrm{mm}^{3}$, core temperature $<36{ }^{\circ} \mathrm{C}$, hypotension requiring aggressive fluid resuscitation).

Healthcare-associated pneumonia (HCAP) was defined as patients with pneumonia that fulfilled any one of the following criteria: (1) hospitalization for more than $48 \mathrm{~h}$ in the last 90 days; (2) residence in a long-term care facility; (3) home infusion therapy within 30 days; (4) chronic dialysis within 30 days; or, (5) home wound care during the 30 days preceding admission.

\section{Antimicrobial therapy}

Adequate antibiotic therapy was defined as treatment with at least one agent to which all recovered isolates were susceptible in vitro.

\section{Guideline-concordant and guideline-discordant antibiotic therapy}

Empirical therapy within the first $24 \mathrm{~h}$ of hospitalization was evaluated for concordance or discordance to the 2007 IDSA/ATS guidelines for CAP [7] Patients were considered to have received guideline-concordant antibiotic therapy if they received initial treatment as outlined in Table 1, regardless of any additional antibiotic received. Patients with severe CAP were considered to have received guideline-concordant antibiotic therapy if they received initial treatment according to guidelines for patients with CAP in ICU. Patients who received all other antibiotic regimens were considered to have received guideline-discordant antibiotic therapy.

\section{Outcomes}

Primary outcome was the rate of unfavorable outcome, which included treatment failure (early, late, or both

Table 12007 Infectious Diseases Society of America/American Thoracic Society Guideline Recommendations for empirical therapy for community-acquired pneumonia

Inpatients, non-ICU treatment

A respiratory fluoroquinolone ${ }^{a}$

A nonantipseudomonal $\beta$-lactam ${ }^{\mathrm{b}}$ plus a macrolide

Inpatients, ICU treatment

A nonantipseudomonal $\beta$-lactam ${ }^{\mathrm{b}}$ plus either azithromycin

or a respiratory fluoroquinolone ${ }^{a}$

If Pseudomonas is a concern

An antipneumococcal, antipseudomonal $\beta$-lactam ${ }^{d}$ plus either ciprofloxacin or levofloxacin

or

The above $\beta$-lactam plus an aminoglycoside ${ }^{e}$ and azithromycin or

The above $\beta$-lactam plus an aminoglycoside ${ }^{e}$ and a respiratory fluoroquinolone

ICU: intensive care unit

aLevofloxacin, or moxifloxacin

${ }^{b}$ Cefotaxime, ceftriaxone, ampicillin/sulbactam, or ertapenem

'Azithromycin, clarithromycin, or erythromycin

dPiperacillin-tazobactam, cefepime, imipenem, or meropenem

eAccording to Thai guidelines for the management of adults with communityacquired pneumonia, adding an aminoglycoside is optional. An aminoglycoside may be added to the initial antibiotic regimens only if multidrug resistant Pseudomonas infection is suspected 
early and late) [23] or death during hospital admission. Early treatment failure was defined as clinical deterioration within $72 \mathrm{~h}$ of treatment (including a need for invasive mechanical ventilation or development of shock that was not present within the first $24 \mathrm{~h}$ after admission, or death). Late treatment failure was defined as one of the following criteria: persistent respiratory rate $\geq 30$ breaths/ min (non-intubated patients), a need for invasive mechanical ventilation or development of shock not present at baseline, radiographic progression (increase in pulmonary infiltrates of $\geq 50 \%$ compared to baseline), or death between $72 \mathrm{~h}$ and $120 \mathrm{~h}$ after the initiation of treatment.

Secondary outcome was the number of hospital-free days at 30 days after enrollment into the study. Number of hospital-free days was defined as the number of days from admission to day 30 that the patient was not admitted to the hospital (calculated by subtracting the length of hospital stay from 30).

\section{Statistical analysis}

All data analysis was performed using SPSS Statistics software version 20 (SPSS, Inc., Chicago, IL, USA). Descriptive analysis was performed. Discrete variables are expressed as number and percentage (\%), and continuous variables as either mean \pm standard deviation (SD) or median and interquartile range (IQR). Proportions were compared using chi-square test or Fisher's exact test for categorical variables, and nonparametric Mann-Whitney $\mathrm{U}$-test or unpaired $\mathrm{t}$-test for continuous variables. Statistical significance was defined as $p<0.05$, and all reported $p$-values were two-tailed.

Multivariate analysis was performed with the backward stepwise elimination logistic-regression analysis model. The dependent variable was the rate of unfavorable outcome, and the independent variables were evaluable variables collected at admission that were associated with unfavorable outcome including in the univariate analysis $(p<0.2)$. Variables remaining in the multivariate analysis model that showed a $p$-value $<0.05$ were considered significant.

\section{Results}

\section{Patients}

A total of 108 patients hospitalized with CAP were evaluated for eligibility. Ten of these patients were immunosuppressed and 4 were found to have mycobacterial infection, so these 14 patients were excluded from further analysis. Of the remaining 94 patients, 50 (53.2\%) met the diagnostic criteria for severe CAP. Thirty-six of 50 patients $(72 \%)$ required mechanical ventilation, and $14(28 \%)$ were classified as severe CAP by IDSA/ATS minor criteria. Clinical characteristics, comorbidities, functional status, and clinical outcomes classified according to pneumonia severity are shown in Table 2 .

\section{Microbial etiology}

An etiologic diagnosis was found in 43 (45.8\%) patients, of which 15 (16\%) were definitive and 28 (29.8\%) were presumptive. The most common pathogens identified in patients with severe CAP were Staphylococcus aureus (28.6\%) and Klebsiella pneumoniae (28.6\%), followed by Pseudomonas aeruginosa (17.9\%). The common pathogens identified in patients with non-severe CAP were similar to those identified in patients with severe CAP. However, patients with severe CAP had significantly more positive blood culture than patients with non-severe CAP ( $24 \%$ vs. $4.5 \%$; $p=0.008$ ), as shown in Table 3.

\section{Antibiotics administered}

Initial antibiotic regimens are shown in Table 4. Of all 94 patients with CAP, $40(42.6 \%)$ received initial antibiotic regimens that were discordant with IDSA/ATS guidelines. The most common guideline-discordant antibiotic regimen prescribed was antipseudomonas $\beta$ lactams without quinolone or macrolide. The risk factors for guideline-discordant initial antibiotic selection were severe CAP, prior antibiotics therapy, enteral tube feeding, HCAP, and treatment with antipseudomonas $\beta$ lactams as shown in Table 5.

\section{Outcomes}

The risk factors for unfavorable outcome in univariate analysis for all 94 patients hospitalized with CAP and 50 patients with severe CAP are shown in Table 6 and Table 7, respectively. Only age and initial antibiotic treatment discordant with IDSA/ATS guidelines for CAP in ICU were found to be independent risk factors for unfavorable outcome in multivariate logistic regression analysis as shown in Table 8 . Of note, the initial antibiotic selections prescribed in patients who had unfavorable outcome were modified during the course of treatment more frequently than the initial antibiotic selections in patients who had favorable outcome. In addition, patients with unfavorable outcome had significantly lower number of hospital-free days at 30 days after enrollment into the study than patients with favorable outcome as shown in Table 7.

\section{Discussion}

Several criteria have been proposed to define severe CAP. We used IDSA/ATS 2007 criteria to define severe CAP, given its good performance for predicting ICU admission and mortality [24, 25]. Moreover, this criteria is based mainly on severity of pneumonia rather than other factors, such as age or comorbidities, and it is simple to use.

The result of this study revealed a substantial number of patients with severe CAP managed in general wards with a high rate of unfavorable outcome (50\%). Mortality and treatment failure are two important clinically 
Table 2 Subject demographic, clinical characteristics, and clinical outcomes by severity of community-acquired pneumonia (CAP)

\begin{tabular}{|c|c|c|c|}
\hline & $\begin{array}{l}\text { Severe CAP } \\
(n=50)\end{array}$ & $\begin{array}{l}\text { Non-severe CAP } \\
(n=44)\end{array}$ & $p$-value \\
\hline Age, y & $70.9 \pm 14.8$ & $68.2 \pm 20.3$ & .46 \\
\hline Gender (Female) & $18(36)$ & $19(43.2)$ & .48 \\
\hline Mechanical ventilation & $36(72)$ & 0 & $<.001^{*}$ \\
\hline Minor criteria $\geq 3^{\mathrm{a}}$ & $14(28)$ & 0 & $<.001^{*}$ \\
\hline \multicolumn{4}{|l|}{ Comorbid conditions: } \\
\hline None / Single / Multiple & $9(18) / 21(42) / 20(40)$ & $17(38.6) / 17$ (38.6) / 10 (22.7) & $.05^{*}$ \\
\hline Prior antibiotic therapy ${ }^{b}$ & $21(42)$ & $22(50)$ & .44 \\
\hline ECOG scale $\geq 2^{c}$ & $32(64)$ & $22(50)$ & .17 \\
\hline Enteral tube feeding & $6(12)$ & $3(6.8)$ & .49 \\
\hline HCAP $^{d}$ & $18(36)$ & $12(27.3)$ & .36 \\
\hline Pleural effusion & $3(6)$ & $8(18.2)$ & .07 \\
\hline Albumin, $\mathrm{g} / \mathrm{dL}$ & $2.8 \pm 0.6$ & $3.1 \pm 0.5$ & $.01^{*}$ \\
\hline Globulin, g/dL & $3.7 \pm 0.8$ & $4.1 \pm 0.6$ & $.001^{*}$ \\
\hline Treatment failure & $23(46)$ & $4(9.1)$ & $<.001^{*}$ \\
\hline Death & $14(28)$ & $4(9.1)$ & $.02^{*}$ \\
\hline Unfavorable outcome $e^{e}$ & $25(50)$ & $6(13.6)$ & $<.001^{*}$ \\
\hline Length of stay in hospital, $\mathrm{d}^{\mathrm{f}}$ & $15.5 \pm 12.8$ & $8.3 \pm 4.6$ & $.003^{*}$ \\
\hline Hospital-free day, $d^{g}$ & $11.6 \pm 9.9$ & $19.7 \pm 7.7$ & $<.001^{*}$ \\
\hline
\end{tabular}

Data are presented as mean \pm SD or $n(\%)$, unless otherwise stated. ${ }^{2}$ IDSA/ATS 2007 minor criteria ${ }^{7}{ }^{b}$ Prior antibiotic therapy: systemic antibiotic use in the 90 days prior to this admission. ${ }^{\mathrm{C} E C O G}$ scale: Eastern Cooperative Oncology Group scale of performance status. ${ }^{\mathrm{d} H C A P:}$ Healthcare-associated pneumonia. ${ }^{\mathrm{e} U n f a v o r a b l e}$ outcome includes treatment failure or death during hospital admission. ${ }^{f}$ Length of stay in hospital in patients who survived to hospital discharge. ${ }^{9}$ Number of days from admission to day 30 that the patient was not admitted to the hospital. *Statistically significant difference

relevant outcomes [7] that are consistently measured and evaluated among studies in CAP. Only age and initial antibiotic selection were found to be independent risk factors for unfavorable outcome. Initial antibiotic selection concordant with the guidelines for patients with severe CAP in ICU would likely have reduced the rate of unfavorable outcome in about half of these patients. Apart from mortality, patients with unfavorable outcome required longer hospital stay and more frequent modification of initial antibiotic treatment. These factors also contribute appreciably to a higher cost of treatment.

Comorbid conditions and functional status are important prognostic markers in CAP. However, comorbid conditions and functional status were associated with the unfavorable outcome only in all patients hospitalized with CAP but were not associated with the unfavorable outcome in the subgroup of patients with severe pneumonia. This is most likely explained by the smaller number of patients in the severe pneumonia group. In addition, most of the patients in the severe pneumonia group (82\%) had some comorbid conditions and $64 \%$ of the patients had low functional status (ECOG $\geq 2$ ). The limited sample size would make it difficult to assess the impact of comorbid conditions and functional status on unfavorable outcome in the severe pneumonia group.
The processes of care and adherence to initial antibiotic selection guidelines have been associated with improved survival, reduced treatment failure, and reduced duration of mechanical ventilation of patients with severe CAP in the ICU $[11-14,21,26]$. The processes of care in general wards is limited and usually much lowerintensity than the care provided in the ICU. As such, antibiotic selection is the only intervention that can be improved to effectuate parity between general wards and the ICU. This study is the first to focus specifically on the impact of initial antibiotic selection on the outcomes of patients with severe CAP in general wards.

Most international guidelines recommend empirical therapy that is based on the location of care, with specific recommendations to those managed as outpatients, as inpatients, and in ICUs [7-10]. Severity scores were not originally designed to guide antibiotic prescription. Severe CAP was one of the risk factors for guideline-discordant initial antibiotic selection in this study as shown in Table 5. This may be due to unrecognition of severe CAP in general medical wards or lack of knowledge of the guidelines for management of severe CAP. This guideline-discordant antibiotic selection led to a higher rate of unfavorable outcome among severe CAP patients treated in general wards. Apart from severe CAP, other risk factors associated with guideline-discordant initial antibiotic selection were prior 
Table 3 Microbiological etiology by severity of community-acquired pneumonia (CAP)

\begin{tabular}{|c|c|c|c|c|c|}
\hline & \multirow[t]{2}{*}{$\begin{array}{l}\text { Severe CAP } \\
(n=50)\end{array}$} & \multirow[t]{2}{*}{$\begin{array}{l}\text { Non-severe CAP } \\
(n=44)\end{array}$} & \multicolumn{3}{|l|}{$\begin{array}{l}\text { All patients } \\
(n=94)\end{array}$} \\
\hline & & & Blood or Pleural fluid & Sputum & Total \\
\hline Positive blood culture & $12(24)$ & $2(4.5)$ & $14(14.9)$ & - & $14(14.9)$ \\
\hline Etiological diagnosis & $28(56)$ & $15(34.1)$ & $15(16)$ & $28(29.8)$ & $43(45.8)$ \\
\hline Streptococcus pneumoniae & $2(7.1)$ & 0 & $2(13.3)$ & 0 & $2(4.6)$ \\
\hline Other Streptococcus spp. & $3(10.7)$ & $1(6.7)$ & $4(26.7)$ & 0 & $4(9.3)$ \\
\hline Staphylococcus aureus & $5(17.9)$ & $3(20)$ & $3(20)$ & $5(17.9)$ & $8(18.6)$ \\
\hline Haemophilus influenzae & 0 & $2(13.3)$ & 0 & $2(7.1)$ & $2(4.6)$ \\
\hline Moraxella catarrhalis & $2(7.1)$ & 0 & 0 & $2(7.1)$ & $2(4.6)$ \\
\hline Enterobacteriaceae: & $6(21.4)$ & $4(26.7)$ & $3(20)$ & $7(25)$ & $10(23.3)$ \\
\hline Klebsiella pneumoniae & $5(17.9)$ & $2(13.3)$ & $2(13.3)$ & $5(17.9)$ & $7(16.3)$ \\
\hline Escherichia coli & $1(3.6)$ & 0 & $1(6.7)$ & 0 & $1(2.3)$ \\
\hline Others & 0 & $2(13.3)$ & 0 & $2(7.1)$ & $2(4.6)$ \\
\hline Pasteurella spp. & $1(3.6)$ & 0 & $1(6.7)$ & 0 & $1(2.3)$ \\
\hline Potentially drug-resistant bacteria: & $13(46.4)$ & $8(53.3)$ & $2(13.3)$ & $19(67.9)$ & $21(48.8)$ \\
\hline Pseudomonas aeruginosa & $5(17.9)$ & $3(20)$ & 0 & $8(28.6)$ & $8(18.6)$ \\
\hline ESBL-positive Enterobacteriaceae* & $4(14.3)$ & $1(6.7)$ & $1(6.7)$ & $4(14.3)$ & $5(11.6)$ \\
\hline Acinetobacter spp. & $2(7.1)$ & $4(26.7)$ & $1(6.7)$ & $5(17.9)$ & $6(13.9)$ \\
\hline Stenotrophomonas maltophilia & 0 & $1(6.7)$ & 0 & $1(3.6)$ & $1(2.3)$ \\
\hline Methicillin resistant Staphylococcus aureus & $3(10.7)$ & $1(6.7)$ & 0 & $4(14.3)$ & $4(9.3)$ \\
\hline Polymicrobials & $4(14.3)$ & $5(33.3)$ & 0 & $9(32.1)$ & $9(20.9)$ \\
\hline
\end{tabular}

Data are presented as $\mathrm{n}(\%) .{ }^{*} \mathrm{ESBL}$ : extended spectrum beta-lactamase

Table 4 Initial antibiotics treatment and clinical outcomes by severity of community-acquired pneumonia (CAP)

\begin{tabular}{|c|c|c|c|c|}
\hline & $\begin{array}{l}\text { All Patients } \\
(n=94)\end{array}$ & $\begin{array}{l}\text { Severe CAP } \\
(n=50)\end{array}$ & $\begin{array}{l}\text { Non-severe CAP } \\
(n=44)\end{array}$ & $p$-value \\
\hline Etiological diagnosis & $43(45.7)$ & $28(56)$ & $15(34.1)$ & $.03^{*}$ \\
\hline Positive blood culture & $14(14.9)$ & $12(24)$ & $2(4.5)$ & $.008^{*}$ \\
\hline Potentially drug-resistance bacteria & $21(22.3)$ & $13(46.4)$ & $8(53.3)$ & .36 \\
\hline Combination therapy & $57(60.6)$ & $30(60)$ & $27(61.4)$ & .89 \\
\hline Guideline-concordant antibiotic therapy ${ }^{a}$ & $54(57.4)$ & $24(48)$ & $30(68.2)$ & $.048^{*}$ \\
\hline 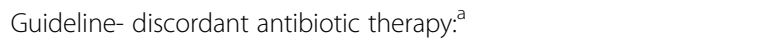 & $40(42.6)$ & $26(52)$ & $14(31.8)$ & \\
\hline$\beta$-lactams without quinolone or macrolide: & $33(35.1)$ & $20(40)$ & $13(29.5)$ & \\
\hline Nonantipseudomonas $\beta$-lactams without quinolone or macrolide & $9(9.6)$ & $4(8)$ & $5(11.4)$ & \\
\hline Antipseudomonas $\beta$-lactams without quinolone or macrolide & $24(25.5)$ & $16(32)$ & $8(18.2)$ & \\
\hline Quinolone without $\beta$-lactams & $5(5.3)$ & $5(10)$ & 0 & \\
\hline Macrolide without $\beta$-lactams & $2(2.1)$ & $1(2)$ & $1(2.3)$ & \\
\hline Inadequate initial antibiotic treatment ${ }^{b}$ & $11 / 43(25.6)$ & $9 / 28(32.1)$ & 2/15 (13.3) & .28 \\
\hline Initial antibiotic regimen was modified & $37(39.4)$ & $26(52)$ & $11(25)$ & $.008^{*}$ \\
\hline Treatment failure & $27(28.7)$ & $23(46)$ & $4(9.1)$ & $<.001^{*}$ \\
\hline Death & $18(19.1)$ & $14(28)$ & $4(9.1)$ & $.02^{*}$ \\
\hline Unfavorable outcome $^{c}$ & $31(32.9)$ & $25(50)$ & $6(13.6)$ & $<.001^{*}$ \\
\hline Hospital-free day, $d^{d}$ & $15.4 \pm 9.8$ & $11.6 \pm 9.9$ & $19.7 \pm 7.7$ & $<.001^{*}$ \\
\hline
\end{tabular}

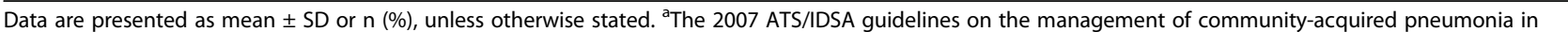

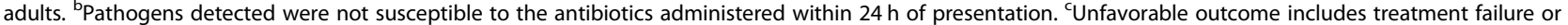
death during hospital admission. ${ }^{d}$ Number of days from admission to day 30 that the patient was not admitted to the hospital. *Statistically significant difference 
Table 5 Risk factors for Infectious Diseases Society of America/American Thoracic Society Guideline - discordant initial antibiotic selection

\begin{tabular}{|c|c|c|c|}
\hline & $\begin{array}{l}\text { Guidelines Concordance } \\
(n=54)\end{array}$ & $\begin{array}{l}\text { Guidelines Discordance } \\
(n=40)\end{array}$ & $p$-value \\
\hline Age, y & $68.5 \pm 15.9$ & $71.3 \pm 19.6$ & .44 \\
\hline Gender (Female) & $28(51.8)$ & $9(22.5)$ & $.004^{*}$ \\
\hline Severe community-acquired pneumonia & $24(44.4)$ & $26(65)$ & $.048^{*}$ \\
\hline \multicolumn{4}{|c|}{ Comorbid conditions: } \\
\hline None & $17(31.5)$ & $9(22.5)$ & .5 \\
\hline Single & $22(40.7)$ & $16(40)$ & \\
\hline Multiple & $15(27.8)$ & $15(37.5)$ & \\
\hline Prior antibiotic therapy ${ }^{a}$ & $20(37)$ & $23(57.5)$ & $.049^{*}$ \\
\hline $\mathrm{ECOG} \geq 2^{\mathrm{b}}$ & $28(51.8)$ & $26(65)$ & .2 \\
\hline Enteral tube feeding & $2(3.7)$ & $7(17.5)$ & $.03^{*}$ \\
\hline Healthcare-associated pneumonia & $11(20.4)$ & $19(47.5)$ & $.005^{*}$ \\
\hline Pleural effusion & $11(20.4)$ & 0 & $.002^{*}$ \\
\hline \multicolumn{4}{|c|}{ Initial antibiotic treatment: } \\
\hline Nonantipseudomonas $\beta$-lactams & $42(77.8)$ & $10(25)$ & $<.001^{*}$ \\
\hline Antipseudomonas $\beta$-lactams & $3(5.6)$ & $24(60)$ & $<.001^{*}$ \\
\hline Macrolide & $43(79.6)$ & $2(5)$ & $<.001^{*}$ \\
\hline Quinolone & $11(20.4)$ & $5(12.5)$ & .31 \\
\hline
\end{tabular}

Data are presented as mean \pm SD or $n(\%)$, unless otherwise stated

aPrior antibiotic therapy: systemic antibiotic use in the 90 days prior to this admission. ${ }^{b} \mathrm{ECOG}$ scale: Eastern Cooperative Oncology Group scale of performance status. *Statistically significant difference

Table 6 Clinical characteristics and clinical outcomes of all patients hospitalized with community-acquired pneumonia (CAP) and patients with severe CAP

\begin{tabular}{|c|c|c|c|c|c|c|}
\hline & \multicolumn{3}{|l|}{ All Patients } & \multicolumn{3}{|l|}{ Severe CAP } \\
\hline & $\begin{array}{l}\text { Favorable Outcome }{ }^{\dagger} \\
(n=63)\end{array}$ & $\begin{array}{l}\text { Unfavorable Outcome }{ }^{\dagger} \\
(n=31)\end{array}$ & $p$-value & $\begin{array}{l}\text { Favorable Outcome }{ }^{\dagger} \\
(n=25)\end{array}$ & $\begin{array}{l}\text { Unfavorable Outcome } \\
(n=25)\end{array}$ & $p$-value \\
\hline Age, y & $65.6 \pm 18.5$ & $77.9 \pm 11.8$ & $<.001^{*}$ & $65.5 \pm 15.7$ & $76.4 \pm 11.7$ & $.008^{*}$ \\
\hline Gender (Female) & $25(39.7)$ & $12(38.7)$ & .93 & $9(36)$ & $9(36)$ & 1 \\
\hline Comorbid conditions: & & & $.04^{*}$ & & & .65 \\
\hline None & $22(34.9)$ & $4(12.9)$ & & $6(24)$ & $3(12)$ & \\
\hline Single & $25(39.7)$ & $13(41.9)$ & & $10(40)$ & $11(44)$ & \\
\hline Multiple & $16(25.4)$ & $14(45.2)$ & & $9(36)$ & $11(44)$ & \\
\hline Prior antibiotic therapy ${ }^{a}$ & $29(46)$ & $14(45.2)$ & .94 & $10(40)$ & $11(44)$ & .77 \\
\hline$E C O G \geq 2^{b}$ & $31(49.2)$ & $23(74.2)$ & $.02^{*}$ & $11(44)$ & $7(28)$ & .24 \\
\hline Enteral tube feeding & $5(7.9)$ & $4(12.9)$ & .47 & $3(12)$ & $3(12)$ & 1 \\
\hline $\mathrm{HCAP}^{\mathrm{C}}$ & $20(31.7)$ & $10(32.3)$ & .96 & $11(44)$ & $7(28)$ & .24 \\
\hline Pleural effusion & $7(11.1)$ & $4(12.9)$ & 1 & 0 & $3(12)$ & .23 \\
\hline Albumin, g/dL & $3 \pm 0.5$ & $2.9 \pm 0.6$ & .24 & $2.9 \pm 0.5$ & $2.8 \pm 0.7$ & .84 \\
\hline Globulin, g/dL & $3.9 \pm 0.6$ & $3.7 \pm 0.9$ & .26 & $3.7 \pm 0.6$ & $3.6 \pm 1$ & .79 \\
\hline
\end{tabular}

Data are presented as mean \pm SD or $n(\%)$, unless otherwise stated. ${ }^{\dagger}$ Unfavorable outcome includes treatment failure or death during hospital admission. ${ }^{a}$ Prior antibiotic therapy: systemic antibiotic use in the 90 days prior to this admission. ${ }^{b}$ ECOG scale: Eastern Cooperative Oncology Group scale of performance status

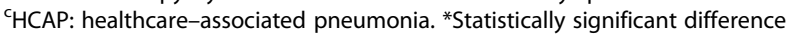


Table 7 Initial antibiotics treatment and clinical outcomes of all patients hospitalized with community-acquired pneumonia (CAP) and patients with severe CAP

\begin{tabular}{|c|c|c|c|c|c|c|}
\hline \multirow[t]{2}{*}{ Initial antibiotics treatment } & \multicolumn{3}{|l|}{ All Patients } & \multicolumn{3}{|l|}{ Severe CAP } \\
\hline & $\begin{array}{l}\text { Favorable } \\
\text { Outcome }^{\dagger} \\
(n=63)\end{array}$ & $\begin{array}{l}\text { Unfavorable } \\
\text { Outcome }{ }^{\dagger} \\
(n=31)\end{array}$ & $p$-value & $\begin{array}{l}\text { Favorable } \\
\text { Outcome }^{\dagger} \\
(n=25)\end{array}$ & $\begin{array}{l}\text { Unfavorable } \\
\text { Outcome }^{\dagger} \\
(n=25)\end{array}$ & $p$-value \\
\hline \multicolumn{7}{|l|}{ Antibiotic classes: } \\
\hline Nonantipseudomonas $\beta$-lactams & $37(58.7)$ & $15(48.4)$ & .38 & $14(56)$ & $12(48)$ & .57 \\
\hline Antipseudomonas $\beta$-lactams & $15(23.8)$ & $12(38.7)$ & .13 & $8(32)$ & $10(40)$ & .56 \\
\hline Macrolide (M) & $35(55.6)$ & $10(32.3)$ & $.03^{*}$ & $16(64)$ & $7(28)$ & $.01^{*}$ \\
\hline Quinolone (Q) & $10(15.9)$ & $6(19.3)$ & .67 & $2(8)$ & $5(20)$ & .42 \\
\hline Combination therapy & 39 (61.9) & $18(58.1)$ & .72 & $16(64)$ & $14(56)$ & .56 \\
\hline Guideline-concordant treatment ${ }^{\mathrm{a}}$ & $42(66.7)$ & $12(38.7)$ & $.01^{*}$ & $16(64)$ & $8(32)$ & $.02^{*}$ \\
\hline 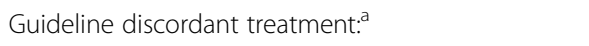 & $21(33.3)$ & $19(61.3)$ & $.01^{*}$ & $9(36)$ & $17(68)$ & $.02^{*}$ \\
\hline$\beta$-lactams without $\mathrm{Q}$ or $\mathrm{M}:$ & 18 (28.6) & $15(48.4)$ & & $7(28)$ & $13(52)$ & \\
\hline Nonantipseudomonas $\beta$-lactams without $\mathrm{Q}$ or $\mathrm{M}$ & $5(7.9)$ & $4(12.9)$ & & 0 & $4(16)$ & \\
\hline Antipseudomonas $\beta$-lactams without Q or M & $13(20.6)$ & $11(35.5)$ & & $7(28)$ & $9(36)$ & \\
\hline Q without $\beta$-lactams & $1(1.6)$ & $4(12.9)$ & & $1(4)$ & $4(16)$ & \\
\hline $\mathrm{M}$ without $\beta$-lactams & $2(3.2)$ & 0 & & $1(4)$ & 0 & \\
\hline Inadequate initial antibiotic treatment ${ }^{b}$ & $7(11.1)$ & $4(12.9)$ & 1 & $5(20)$ & $4(16)$ & 1 \\
\hline Initial antibiotic regimen was modified & $13(20.6)$ & $24(77.4)$ & $<.001^{*}$ & $7(28)$ & $19(76)$ & $.001^{*}$ \\
\hline Length of stay in hospital, $\mathrm{d}^{c}$ & $9.9 \pm 8.9$ & $20.2 \pm 11.1$ & $.001^{*}$ & $13.5 \pm 12.9$ & $20.1 \pm 12.1$ & .16 \\
\hline Hospital-free day, $d^{d}$ & $20.6 \pm 5.6$ & $4.8 \pm 7.5$ & $<.001^{*}$ & $18 \pm 7.1$ & $5.2 \pm 8$ & $<.001^{*}$ \\
\hline
\end{tabular}

Data are presented as mean \pm SD or $\mathrm{n}(\%)$, unless otherwise stated. ${ }^{\dagger}$ Unfavorable outcome includes treatment failure or death during hospital admission. ${ }^{\mathrm{a}} \mathrm{The}$ 2007 ATS/IDSA guidelines on the management of community-acquired pneumonia in adults ${ }^{7}$. ${ }^{b}$ Pathogens detected were not susceptible to the antibiotics administered within $24 \mathrm{~h}$ of presentation. ' Length of stay in hospital in patients who survived to hospital discharge. ${ }^{\mathrm{d}}$ Number of days from admission to day 30 that the patient was not admitted to the hospital. *Statistically significant difference

Table 8 Risk factors of unfavorable outcome ${ }^{\dagger}$ in patients hospitalized with community-acquired pneumonia (CAP) by univariate and multivariate analyses

\begin{tabular}{|c|c|c|c|}
\hline & \multirow{2}{*}{$\begin{array}{l}\text { Univariate analysis } \\
p \text {-value }\end{array}$} & \multicolumn{2}{|c|}{ Multivariate analysis } \\
\hline & & $p$-value & OR $(95 \% \mathrm{Cl})$ \\
\hline \multicolumn{4}{|c|}{ ALL hospitalized patients with CAP $(n=94)$} \\
\hline Age & $<.001^{*}$ & $.002^{*}$ & $1.07(1.03-1.1)$ \\
\hline Comorbid conditions & $.04^{*}$ & NS & \\
\hline$E C O G \geq 2^{a}$ & $.02^{*}$ & NS & \\
\hline Severe CAP & $<.001^{*}$ & $.001^{*}$ & $7.9(2.4-26.3)$ \\
\hline Guideline-discordant treatment $^{\mathrm{b}}$ & $.01 *$ & .079 & $2.5(0.9-7.1)$ \\
\hline \multicolumn{4}{|c|}{ Hospitalized patients with severe CAP $(n=50)$} \\
\hline Age & $.008^{*}$ & $.01^{*}$ & $1.1(1.01-1.1)$ \\
\hline Comorbid conditions & .65 & NS & \\
\hline$E C O G \geq 2^{a}$ & .24 & NS & \\
\hline Guideline-discordant treatment $^{\mathrm{b}}$ & $.02^{*}$ & $.02^{*}$ & $4.6(1.3-17.1)$ \\
\hline
\end{tabular}

OR: odds ratio. $\mathrm{Cl}$ : confidence interval

'Unfavorable outcome includes treatment failure or death during hospital admission

${ }^{a}$ ECOG scale: Eastern Cooperative Oncology Group scale of performance status

${ }^{\text {b}}$ The 2007 ATS/IDSA guidelines on the management of community-acquired pneumonia in adults ${ }^{7}$

*Statistically significant difference. NS: not significant difference 
antibiotic therapy, enteral tube feeding, HCAP, and treatment with antipseudomonas $\beta$-lactams. These factors were related to physician concern about the possible presence of multidrug-resistant pathogens that cause CAP, which is a growing problem in many countries - including our country. Put another way, these physicians actively conclude that their patients are at-risk for specific types of pathogens, and that, therefore, the guidelines may not apply. This undue attention to multidrug-resistant pathogens resulted in their decision to drop the second antibiotic, especially the drug required for coverage against atypical copathogens.

The rate of microbial etiology identification in this study $(45.8 \%)$ was comparable to that of other studies $[7$, $27,28]$. The pattern of causative organisms identified in this study was more similar to hospital-acquired pneumonia than community-acquired infection, with high prevalence of potentially drug-resistant bacteria. There are many reports, especially from Asian countries, of increasing prevalence of potentially drug-resistant bacteria in CAP [29]. However, most of these potentially drugresistant bacteria were identified by sputum culture. As such, these culture findings may partly represent colonization. Because this study was a single center study in general medical wards with substantial number of critically illed patients, with small sample size, it may not represent the overall epidemiologic data of the etiology of CAP in general medical wards.

It is not clear how the initial antibiotic regimens according to IDSA/ATS guidelines achieved its beneficial effect for patients with severe CAP in this study. Guideline compliance may only be a surrogate marker for quality of care overall. The most common guideline-discordant regimen was $\beta$-lactams without quinolone or macrolide, which resulted in lack of coverage for atypical pathogens. We did not investigate for atypical pathogens in this study. However, a previous study from Thailand revealed atypical pathogens to be responsible for about $30 \%$ of the patients hospitalized with CAP [30]. Several observational studies suggested that combination therapy improves survival in the subset of the most severe patients with bacteremic pneumococcal infection [31-33]. The patients with severe CAP in this study also had a higher rate of positive blood culture than patients with non-severe CAP. However, only the combination therapy according to the guidelines that included both $\beta$-lactams with quinolone or macrolide, was associated with favorable outcome. Most of the patients in this study that received combination therapy according to the guidelines were given macrolides. Macrolides exert broad-ranging immunomodulatory effects, and its combination with other antibiotics may explain the higher rates of favorable outcome [34].

The present study has several potential limitations. First, our study was a secondary analysis of an observational study with limited sample size, and the results may be subject to the effects of confounders that were not controlled for in regression analyses. Second, only one process (initial antibiotic selection) was analyzed not composite processes. It was, therefore, not possible to determine whether or not guideline-concordant antibiotic selection was associated with better overall care, or how this affected the results of this study. Third, therapeutic changes introduced after the initial antibiotic treatment was prescribed were not investigated; however, a study reported that such changes may not influence the final outcome [35]. Fourth, the time from admission to first administration of antibiotics has been suggested as a key predictor of outcome, but this information was not evaluated in the present study.

\section{Conclusions}

A substantial number of patients with severe CAP were managed in general wards with a high rate of unfavorable outcome. Adherence to the IDSA/ATS guidelines for initial antibiotic treatment of severe CAP in the ICU may contribute to a lower rate of unfavorable outcome, and a higher number of hospital-free days. Severe CAP outside ICU should be recognized for appropriate initial antibiotic selection to improve outcomes.

\section{Abbreviations \\ ATS: American Thoracic Society; CAP: community-acquired pneumonia; ECOG: Eastern Cooperative Oncology Group; HCAP: healthcare-associated pneumonia; IDSA: Infectious Diseases Society of America}

\section{Acknowledgements \\ The authors would like to express their appreciation to Khemajira Karaketklang, for statistical assistance.}

\section{Authors' contributions}

P.W. is guarantor for the entire manuscript. P.W. contributed to the conception, hypothesis, outline, and design of the study; data acquisition; data analysis; drafting the article; and substantial involvement in its revision prior to submission. N. C. contributed to the design of the study; data acquisition; drafting the article; and substantial involvement in its revision prior to submission. All authors have read and approved the manuscript.

\section{Funding}

This research did not receive any specific grant from funding agencies in the public, commercial, or not-for-profit sectors.

\section{Availability of data and materials}

The datasets used in this study are available from the corresponding author upon reasonable request.

\section{Ethics approval and consent to participate}

The study protocol was approved by the Siriraj Hospital Ethics Committee on Human Research (No. SIRB 391/2555-EC1). Written informed consent for inclusion in the study was obtained from each patient or the patient's next of kin.

Consent for publication

Not applicable.

Competing interests

The authors declare that they have no competing interests in this section. 


\section{Author details}

'Division of Respiratory Disease, Department of Medicine, Siriraj Hospital, Mahidol University, Bangkoknoi, Bangkok 10700, Thailand. 'Bamrasnaradura Infectious Disease Institute, Tiwanon Road, Amphur Mueng, Nonthaburi 11000, Thailand.

\section{Received: 4 October 2018 Accepted: 20 September 2019}

\section{0.}

\section{References}

1. Fine MJ, Smith MA, Carson CA, Mutha SS, Sankey SS, Weissfeld LA, et al. Prognosis and outcomes of patients with community acquired pneumonia: a meta-analysis. JAMA. 1996;275(2):134-41.

2. Welte T, Torres A, Nathwani D. Clinical and economic burden of communityacquired pneumonia among adults in Europe. Thorax. 2012;67:71-9.

3. Lozano R, Naghavi M, Foreman K, Lim S, Shibuya K, Aboyans V, et al. Global and regional mortality from 235 causes of death for 20 age groups in 1990 and 2010: a systematic analysis for the global burden of disease study 2010. Lancet. 2012;380:2095-128.

4. Etyang AO, Scott JA. Medical causes of admissions to hospital among adults in Africa: a systematic review. Glob Health Action. 2013;6:1-14.

5. Takahashi K, Suzuki M, Minh Le N, Anh NH, Huong LT, Son TV, et al. The incidence and aetiology of hospitalised community-acquired pneumonia among Vietnamese adults: a prospective surveillance in Central Vietnam. BMC Infect Dis. 2013;13:296.

6. Restrepo Ml, Anzueto A. Severe community-acquired pneumonia. Infect Dis Clin N Am. 2009;23(3):503-20.

7. Mandell LA, Wunderink RG, Anzueto A, Bartlett JG, Campbell GD, Dean NC, et al. Infectious Diseases Society of America/American Thoracic Society consensus quidelines on the management of community acquired pneumonia in adults. Clin Infect Dis. 2007;44(Suppl 2):S27-72.

8. Menendez R, Torres A, Aspa J, Capelastegui A, Prat C, Rodríguez de Castro F. Community acquired pneumonia. New guidelines of the Spanish Society of Chest Diseases and Thoracic Surgery (SEPAR). Arch Bronconeumol. 2010;46:543-58.

9. Woodhead M, Blasi F, Ewig S, Garau J, Huchon G, leven M, et al. Guidelines for the management of adult lower respiratory tract infections-summary. Clin Microbiol Infect. 2011;17(suppl 6):1-24.

10. Mandell LA, Marrie TJ, Grossman RF, Chow AW, Hyland RH. Summary of Canadian guidelines for the initial management of community-acquired pneumonia: an evidence-based update by the Canadian infectious disease society and the Canadian thoracic society. Can J Infect Dis. 2000;11:237-48.

11. Bodí M, Rodríguez A, Solé-Violán J, Gilavert MC, Garnacho J, Blanquer J, et al. Community-acquired pneumonia intensive care units (CAPUCI) study investigators. Antibiotic prescription for community-acquired pneumonia in the intensive care unit: impact of adherence to Infectious Diseases Society of America guidelines on survival. Clin Infect Dis. 2005;41(12):1709-16.

12. Frei CR, Attridge RT, Mortensen EM, Restrepo MI, Yu Y, Oramasionwu CU, et al. Guideline-concordant antibiotic use and survival among patients with community-acquired pneumonia admitted to the intensive care unit. Clin Ther. 2010;32(2):293-9.

13. Mene'ndez R, Torres A, Reyes S, Zalacain R, Capelastegui A, Aspa J, et al. Initial management of pneumonia and sepsis: factors associated with improved outcome. Eur Respir J. 2012;39(1):156-62.

14. Shorr AF, Bodi M, Rodriguez A, Sole-Violan J, Garnacho-Montero J, Rello J. CAPUCI study investigators. Impact of antibiotic guideline compliance on duration of mechanical ventilation in critically ill patients with communityacquired pneumonia. Chest. 2006;130(1):93-100.

15. Singer DE, Carr PL, Mulley AG, Thibault GE. Rationing intensive care--physician responses to a resource shortage. N Engl J Med. 1983;309:1155-60.

16. Yoshiya I, Baik SW. Critical care in Japan and Korea. The market of excellence. Crit care. Clin. 1997;13(2):267-85.

17. Sinuff $T$, Kahnamoui $K$, Cook DJ, Luce JM, Levy MM. Values ethics and rationing in critical care task force. Rationing critical care beds: a systematic review. Crit Care Med. 2004;32(7):1588-97.

18. Hersch M, Sonnenblick M, Karlic A, Einav S, Sprung CL, Izbicki G. Mechanical ventilation of patients hospitalized in medical wards VS the intensive care unit--an observational, comparative study. J Crit Care. 2007;22:13-7.

19. Phua J, Ngerng WJ, Lim TK. The impact of a delay in intensive care unit admission for community-acquired pneumonia. Eur Respir J. 2010;36(4):826-33.
20. Ewig S, de Roux A, Bauer T, García E, Mensa J, Niederman M, et al. Validation of predictive rules and indices of severity for community acquired pneumonia. Thorax. 2004;59:421-7.

21. Lim HF, Phua J, Mukhopadhyay A, Ngerng WJ, Chew MY, Sim TB, et al. IDSA/ATS minor criteria aid pre-intensive care unit resuscitation in severe community-acquired pneumonia. Eur Respir J. 2014;43(3):852-62.

22. Jeon $\mathrm{K}$, Yoo H, Jeong BH, Park HY, Koh WJ, Suh GY, et al. Functional status and mortality prediction in community-acquired pneumonia. Respirology. 2017;22(7):1400-6

23. Menendez R, Torres A. Treatment failure in community-acquired pneumonia. Chest. 2007;132(4):1348-55.

24. Liapikou A, Ferrer M, Polverino E, Balasso V, Esperatti M, Piñer R, et al. Severe community-acquired pneumonia: validation of the Infectious Diseases Society of America/ American Thoracic Society guidelines to predict an intensive care unit admission. Clin Infect Dis. 2009:48(4):377-85.

25. Chalmers JD, Taylor JK, Mandal P, Choudhury G, Singanayagam A, Akram AR, et al. Validation of the Infectious Diseases Society of America/American Thoratic society minor criteria for intensive care unit admission in communityacquired pneumonia patients without major criteria or contraindications to intensive care unit care. Clin Infect Dis. 2011;53(6):503-11.

26. Woodhead M, Welch CA, Harrison DA, Bellingan G, Ayres JG. Communityacquired pneumonia on the intensive care unit: secondary analysis of 17,869 cases in the ICNARC case mix Programme database. Crit Care. 2006;10(suppl 2):S1.

27. Matsushima T, Miyashita N, File TM Jr. Etiology and management of communityacquired pneumonia in Asia. Curr Opin Infect Dis. 2002;15(2):157-62.

28. Torres A, Blasi F, Peetermans WE, Viegi G, Welte T. The aetiology and antibiotic management of community-acquired pneumonia in adults in Europe: a literature review. Eur J Clin Microbiol Infect Dis. 2014;33(7):1065-79.

29. Shindo Y, Hasegawa Y. Regional differences in antibiotic-resistant pathogens in patients with pneumonia: implications for clinicians. Respirology. 2017; 22(8):1536-46.

30. Wattanathum A, Chaoprasong C, Nunthapisud P, Chantaratchada S, Limpairojn N, Jatakanon, et al. Community-acquired pneumonia in Southeast Asia: the microbial differences between ambulatory and hospitalized patients. Chest. 2003;123(5):1512-9.

31. Waterer GW, Somes GW, Wunderink RG. Monotherapy may be suboptimal for severe bacteremic pneumococcal pneumonia. Arch Intern Med. 2001; 161:1837-42.

32. Martinez JA, Horcajada JP, Almela M, Marco F, Soriano A, Garcia E, et al. Addition of a macrolide to a beta-lactam-based empirical antibiotic regimen is associated with lower in-hospital mortality for patients with bacteremic pneumococcal pneumonia. Clin Infect Dis. 2003;36:389-95.

33. Baddour LM, Yu VL, Klugman KP, Feldman C, Ortqvist A, Rello J, et al. Combination antibiotic therapy lowers mortality among severely ill patients with pneumococcal bacteremia. Am J Respir Crit Care Med. 2004;170:440-4.

34. Sligl WI, Asadi L, Eurich DT, Tjosvold L, Marrie TJ, Majumdar SR. Macrolides and mortality in critically ill patients with community-acquired pneumonia: a systematic review and meta-analysis. Crit Care Med. 2014:42:420-32.

35. Gleason PP, Meehan TP, Fine JM, Galusha DH, Fine MJ. Associations between initial antimicrobial therapy and medical outcomes for hospitalized elderly patients with pneumonia. Arch Intern Med. 1999;159:2562-72.

\section{Publisher's Note}

Springer Nature remains neutral with regard to jurisdictional claims in published maps and institutional affiliations.

Ready to submit your research? Choose BMC and benefit from:

- fast, convenient online submission

- thorough peer review by experienced researchers in your field

- rapid publication on acceptance

- support for research data, including large and complex data types

- gold Open Access which fosters wider collaboration and increased citations

- maximum visibility for your research: over $100 \mathrm{M}$ website views per year

At $\mathrm{BMC}$, research is always in progress.

Learn more biomedcentral.com/submissions 